\title{
Development of New Cryocooler Regenerator Materials - Ductile Intermetallic Compounds
}

\author{
K.A. Gschneidner, Jr. ${ }^{1,2}$, A.O. Pecharsky ${ }^{1}$, and V.K. Pecharsky ${ }^{1,2}$ \\ ${ }^{\mathrm{I}}$ Materials and Engineering Physics Program, Ames Laboratory \\ Iowa State University, Ames, Iowa 50011-3020 \\ ${ }^{2}$ Department of Materials Science and Engineering \\ Iowa State University, Ames, Iowa 50011-2300, USA
}

\begin{abstract}
The volumetric heat capacities of a number of binary and ternary Er- and Tm-based intermetallic compounds, which exhibited substantial ductilities, were measured from $\sim 3$ to $\sim 350 \mathrm{~K}$. They have the RM stoichiometry (where $\mathrm{R}=\mathrm{Er}$ or $\mathrm{Tm}$, and $\mathrm{M}$ is a main group or transition metal) and crystallize in the CsCl-type structure. The heat capacities of the Tm-based compounds are in general larger than the corresponding Er-based materials. Many of them have heat capacities which are significantly larger than those of the low temperature $(<15 \mathrm{~K})$ prototype cryocooler regenerator materials $\mathrm{HoCu}_{2}, \mathrm{Er}_{3} \mathrm{Ni}$ and $\mathrm{ErNi}$. Utilization of the new materials as regenerators in the various cryocoolers should improve the performance of these refrigeration units for cooling below $15 \mathrm{~K}$.
\end{abstract}

\section{INTRODUCTION}

Lanthanide materials have been used as low temperature $(<20 \mathrm{~K})$ regenerators since 1990 because of their large magnetic entropies at their magnetic ordering temperatures ${ }^{1}$. This development allowed Toshiba scientists ${ }^{2,3}$ to reduce the low temperature limit of a two stage Gifford-McMahon cryocooler from 10 to $4 \mathrm{~K}$ by replacing some of the $\mathrm{Pb}$ with $\mathrm{Er}_{3} \mathrm{Ni}$ in the low temperature stage regenerator. Since then, $\mathrm{Nd}^{4}$ and $\mathrm{HoCu}_{2}{ }^{5}$ have been used as replacements for $\mathrm{Er}_{3} \mathrm{Ni}$; and the $\mathrm{Er}_{1-\mathrm{x}} \mathrm{Pr}_{\mathrm{x}}$ alloys $(0 \leq \mathrm{x} \leq 0.50)$ as a substitute for $\mathrm{Pb}^{6,7}$ for cooling down to between 60 and $10 \mathrm{~K} . \mathrm{GdAlO}_{3}\left(\mathrm{~T}_{\mathrm{C}}=3.8 \mathrm{~K}\right)$ has been employed to cool to $4 \mathrm{~K}$ when utilized in the coldest section of a compound regenerator ${ }^{8}$. Below we discuss our latest work on the development of regenerator materials - ductile intermetallic compounds which have high volumetric heat capacities in the vicinity of the magnetic ordering temperatures between 4 and $16 \mathrm{~K}$.

\section{EXPERIMENTAL DETAILS}

The alloys were prepared by arc-melting stoichiometric amounts of the component materials on a water cooled copper hearth under an argon atmosphere. The alloys were generally turned over 6 times (except for ErIr which was turned over 20 times) and remelted to ensure a homogeneous ingot. Weight losses after melting were negligible. The metals used in this study 
were purchased from various commercial sources. The rare earth metals were 95 to 98 atomic percent pure with the major impurities being $\mathrm{O}, \mathrm{C}$ and $\mathrm{N}$, while the non-rare earth metals were $99.9+$ atomic percent pure. The x-ray powder diffraction data were collected on an automated Scintag powder diffractometer using $\mathrm{Cu} \mathrm{K}_{\alpha}$ radiation to check on the phase purity and the crystallography of the samples. All of the samples were found to be single-phase materials within the limitations of the x-ray powder diffraction technique (typically 2 to $5 \mathrm{vol} \%$ of an impurity phase). Most of the intermetallic compound samples were not heat treated because they were single phase alloys after arc-melting. ErRh and ErAu, however, were heat treated for 335 hours ( 2 weeks) at $900^{\circ} \mathrm{C}$ and rapidly quenched to room temperature to retain the $\mathrm{B} 2$ structure. The heat capacities at constant pressure were measured using an adiabatic heat-pulse-type calorimeter ${ }^{9}$ from $\sim 3.5$ to $\sim 350 \mathrm{~K}$ in zero magnetic field.

\section{DUCTLE INTERMETALLIC COMPOUNDS}

Magnetic lanthanide intermetallic compounds exhibit a wide range of magnetic ordering temperatures ranging from less than $1 \mathrm{~K}$ to nearly $1300 \mathrm{~K}$. Of particular interest to the cryocooler industry are those compounds which order magnetically below $20 \mathrm{~K}^{1}$. Although many compounds have high heat capacities at the required temperature and thus would perform well as passive regenerator materials, their mechanical properties are far from ideal. In general, as most stoichiometric compounds, they are inherently brittle. Thus, they are nearly impossible to fabricate into sheets, jelly rolls, wires, and screens, which can be assembled into a regenerator which is more efficient than a packed bed of spheres. Furthermore, because of this brittleness the spheres can decrepitate and eventually leading to the failure of the regenerator and therefore the cryocooler. Thus, if one could make the brittle intermetallic compounds into ductile materials, or if one could find ductile intermetallic phases with suitable thermal properties, either development would be a major breakthrough in improving the efficiency of low temperature cryocoolers. Recently, we have discovered such a family of compounds which have unprecedented ductility (as high as $20 \%$ ) and high fracture-toughness at room temperature ${ }^{10}$. This family of equiatomic compounds, $R M$, is made up of a rare earth (R) and a main group or transition metal (M) atoms, and has the B2, CsCl-type structure (see Fig. 1). There are over 120 known members in this family. Some of these binary RM phase have high heat capacities below $20 \mathrm{~K}$ [e.g. $\mathrm{ErCu}, \mathrm{T}_{\mathrm{O}} \cong 8.5 \mathrm{~K}$ and $13 \mathrm{~K}^{11} ; \mathrm{ErAg} \mathrm{T}_{\mathrm{O}} \cong 15.5 \mathrm{~K}^{\mathrm{i} 2} ; \mathrm{TmCu}, \mathrm{T}_{\mathrm{O}} \cong 6.5$ and $8 \mathrm{~K}^{11,13}$; and $\mathrm{TmAg}, \mathrm{T}_{0} \cong 7 \mathrm{~K}^{13}$ (the ordering temperatures listed here are those found in this study, which may differ slightly from earlier values reported in the literature)], and thus are of interest to the cryocooler community. Indeed, Biwa et al. ${ }^{14}$ have proposed that ErAg be utilized as a

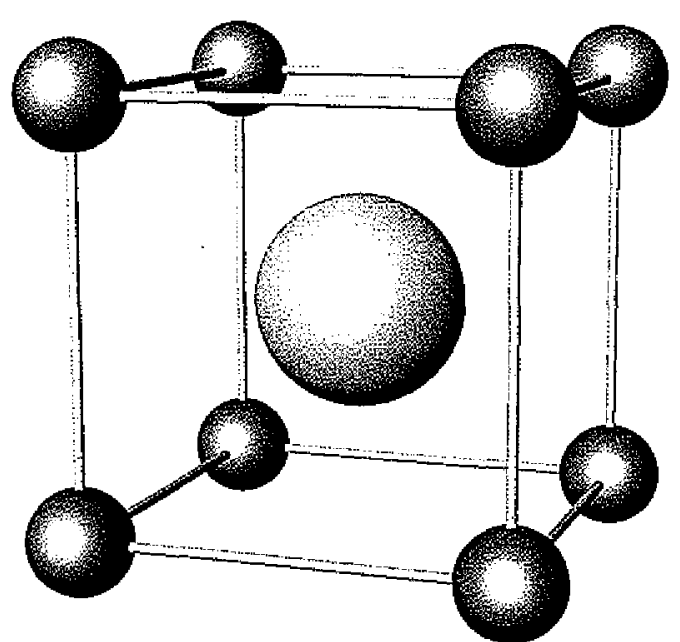

Figure 1. The B2 CsCl-type crystal structure. The larger sphere shown in the center of the unit cell represents the rare earth metal atom, while the smaller spheres on the comers represent the non-rare earth metal (a main group or a transition metal) atom. 


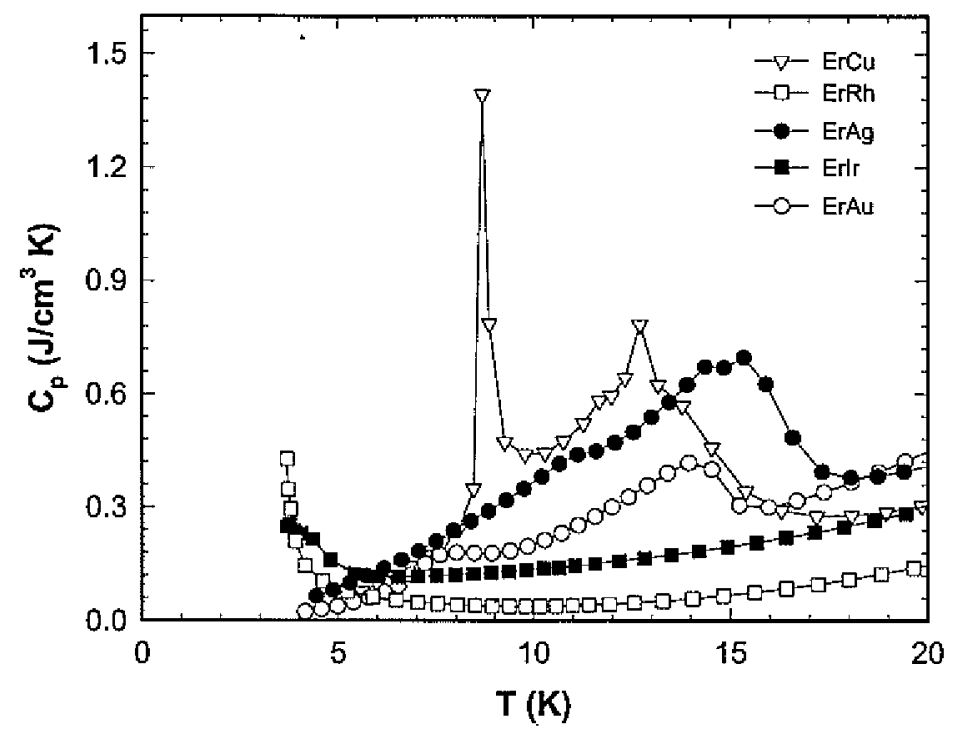

Figure 2. The volumetric heat capacities of ErCu, $\mathrm{ErRh}, \mathrm{ErAg}, \mathrm{ErIr}$ and $\mathrm{ErAu}$ from $\sim 4$ to $20 \mathrm{~K}$.

regenerator material from 9 to $17 \mathrm{~K}$, but they did not realize that this compound is a ductile intermetallic. In addition to their ductilities, these B2 compounds are stable in air and have good oxidation resistance at room temperature.

Alloying studies have been carried out on $\mathrm{ErCu}$ and $\mathrm{TmCu}$ to establish: (1) whether the two ordering peaks can be merged or shifted closer together to design an alloy which would have a larger heat capacity over a broader temperature range, and thus may increase the efficiency of the regenerator; and (2) how much the major heat capacity peak temperature (the lower ordering one) could be shifted upward or downward to give some flexibility in designing regenerators to fit a particular requirement.

\section{RESULTS AND DISCUSSION}

The pure B2 RM binary compounds studied include ErCu, ErRh, ErAg, ErIr, ErAu, TmCu and TmAg. In addition, many ternary $R\left(M_{,} M^{\prime}\right)$ and $\left(R, R^{\prime}\right) M$ compounds were studied, especially the ErCu- and $\mathrm{TmCu}$-base materials. The non-rare earth dopants include $\mathrm{Al}, \mathrm{Mn}, \mathrm{Fe}$, $\mathrm{Ni}, \mathrm{Co}, \mathrm{Zn}, \mathrm{Ga}, \mathrm{Ru}$ and $\mathrm{Ag}$, while the rare earth additives were $\mathrm{Sc}, \mathrm{Y}, \mathrm{La}, \mathrm{Ce}, \mathrm{Pr}, \mathrm{Nd}, \mathrm{Gd}, \mathrm{Tb}$, Dy, Ho, Er, Tm and Lu.

\section{Binary B2 RM Compounds}

The volumetric heat capacities of the binary ErM (where $\mathrm{M}=\mathrm{Cu}, \mathrm{Rh}, \mathrm{Ag}, \mathrm{Ir}, \mathrm{Au}$ ) B2, CsCltype intermetallic compounds are shown in Fig. 2. Of these five compounds, only ErCu has two magnetic ordering temperatures $(-8.5$ and $\sim 12.7 \mathrm{~K})$, while the others probably have one magnetic transition: ErAg at about $16 \mathrm{~K}$, ErAu at about $14 \mathrm{~K}$, and ErRh and ErIr below $4 \mathrm{~K}$. It is possible that ErAu may have a second magnetic transition at about $7.5 \mathrm{~K}$ but this needs to be verified by other physical property measurements such as the magnetic susceptibility or electrical resistivity. The upswing in the volumetric heat capacity below $5 \mathrm{~K}$ of ErRh and ErIr suggests that these two compounds might be good magnetic regenerator materials for cooling below $4 \mathrm{~K}$, but lower temperature heat capacity measurements need to be made to verify the actual peak heat capacity values and their magnetic ordering temperatures. However, the high cost of Rh and Ir will prohibit their widespread use as regenerator materials, regardless of their ordering temperature and heat capacity peak value. 


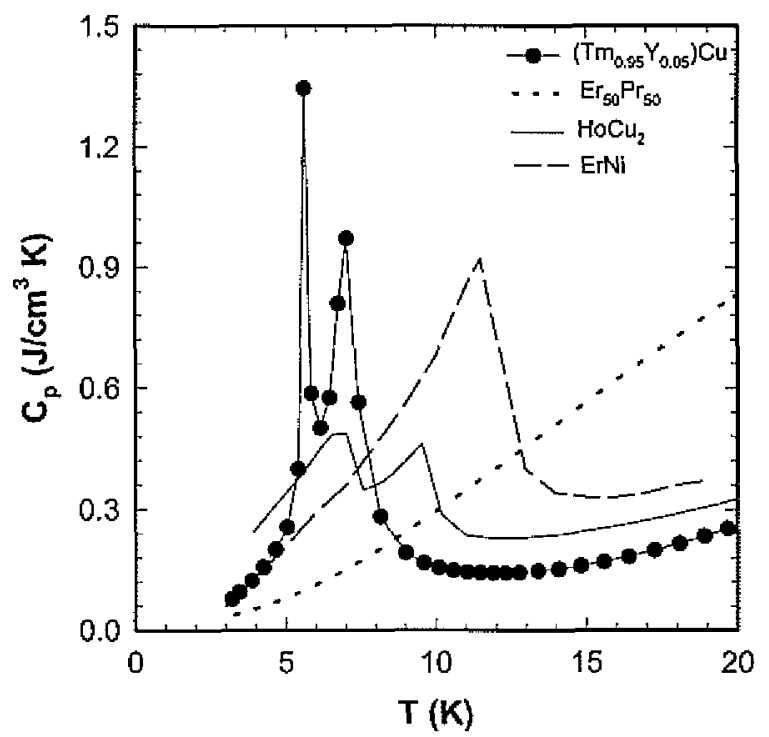

Figure 3. The volumetric heat capacity of $\left(\mathrm{Tm}_{0.95} \mathrm{Y}_{0.05}\right) \mathrm{Cu}$ from $\sim 3$ to $20 \mathrm{~K}$. The corresponding volumetric heat capacities of the cryocooler prototype regenerator materials $\mathrm{Er}_{50} \mathrm{Pr}_{50}, \mathrm{HoCu}_{2}$ and $\mathrm{ErNi}$ are also shown.

$\operatorname{TmAg}$, which orders at $7.5 \mathrm{~K}$, has a maximum heat capacity of $0.7 \mathrm{~J} / \mathrm{cm}^{3} \mathrm{~K}$, which is about $50 \%$ larger than the double peaks of $\mathrm{HoCu}_{2}$, and would make an excellent replacement regenerator material for either $\mathrm{HoCu}_{2}$ or $\mathrm{Er}_{3} \mathrm{Ni}$.

\section{Rare Earth Additions}

The substitutions of $\mathrm{R}=\mathrm{Sc}$, La, $\mathrm{Ce}, \mathrm{Pr}$ and $\mathrm{Nd}$ for $\mathrm{Er}$ in $\left(\mathrm{Er}_{0.9} \mathrm{R}_{0.1}\right) \mathrm{Cu}$ have similar effects: the lower ordering temperature at $\sim 8.5 \mathrm{~K}$ is wiped-out, the heat capacity at the upper peak $(\sim 12.7 \mathrm{~K})$ is greatly reduced and shifted slightly to lower temperatures. The effect of $\mathrm{Y}$ is not nearly as drastic: both peaks are shifted to a lower temperature $(8.5$ to $7 \mathrm{~K}$, and 12.7 to $12.2 \mathrm{~K})$ and the magnitudes of the heat capacity peaks are greatly reduced, especially that of the $8.5 \mathrm{~K}$ peak. A similar behavior is observed for $\mathrm{R}$ substitution of $\mathrm{Tm}$ in $\mathrm{TmCu}$, for $\mathrm{R}=\mathrm{La}, \mathrm{Ce}, \mathrm{Pr}$, and Nd. The substitution of $\mathrm{Y}$ for $\mathrm{Tm}$ in $\mathrm{TmCu}$ is, however, different from the $\left(\mathrm{Er}_{1-\mathrm{x}} \mathrm{Y}_{\mathrm{x}}\right) \mathrm{Cu}$ alloys, where $0 \leq x \leq 0.15$. The temperatures and the peak volumetric heat capacity values of $\mathrm{TmCu}$ are lowered by $Y$ doping. The upper peak temperature drops more rapidly than the lower one, so that they merge for $x=0.15$. The volumetric heat capacity of $\left(\operatorname{Tm}_{0.95} Y_{0.05}\right) C u$ is compared to those of the three low-temperature cryocooler prototype regenerator materials in Fig. 3. This alloy would be an excellent regenerator material for cooling down to $5 \mathrm{~K}$.

The heavy lanthanides behave differently from the light lanthanides in that both peaks of pure $\mathrm{ErCu}$ still remain upon alloying. In the case of $\mathrm{Gd}$ and $\mathrm{Tb}$ dopants the peaks are shifted to a higher temperature and the volumetric heat capacities are considerably reduced. The substitution of Dy and $\mathrm{Ho}$, in contrast to the other lanthanides, hardly has any affect on either the ordering temperature or the volumetric heat capacity, and Ho more so than Dy. For Dy, the temperature spread between the lower and upper ordering peaks is widened by about $2 \mathrm{~K}$ with low transition temperature shifted downward and the upper temperatures upward.

The substitution of Er for Tm (Tm-rich alloys) and Tm for Er (Er-rich alloys) on the volumetric heat capacity in the $\left(\mathrm{Tm}_{1-\mathrm{x}} \mathrm{Er}_{\mathrm{x}}\right) \mathrm{Cu}$ pseudo binary system results in an increase of the upper heat capacity peak value of $\mathrm{ErCu}\left(1.4 \mathrm{~J} / \mathrm{cm}^{3} \mathrm{~K}\right)$ to that of $\mathrm{TmCu}\left(2.8 \mathrm{~J} / \mathrm{cm}^{3} \mathrm{~K}\right)$. The increase, however, is not linear, but has a sinusoid-like shape. The maximum value of the heat capacity for the lower magnetic ordering peak remains essentially constant $\left(1.0 \pm 0.3 \mathrm{~J} / \mathrm{cm}^{3} \mathrm{~K}\right)$ as 


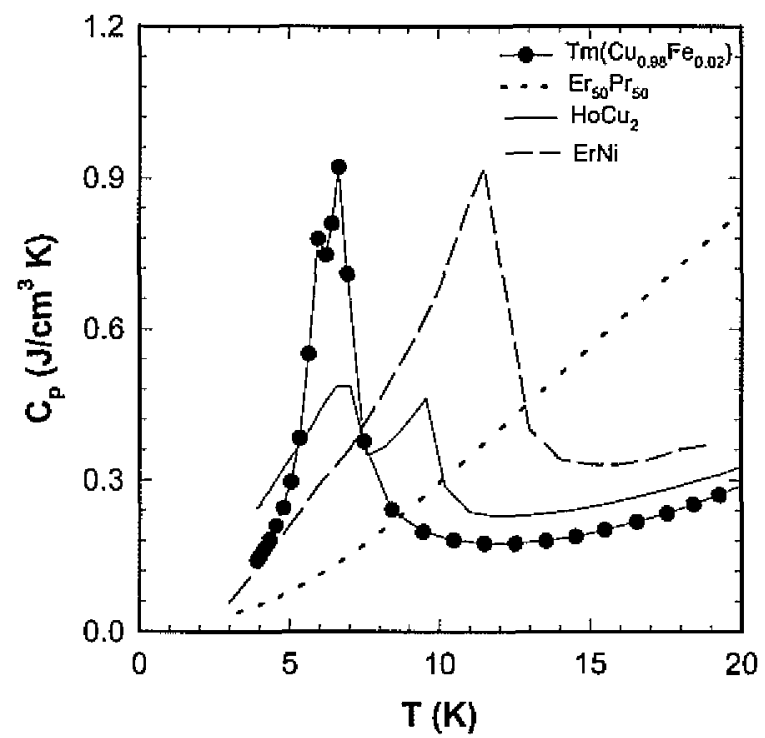

Figure 4. The volumetric heat capacity of $\operatorname{Tm}\left(\mathrm{Cu}_{0.98} \mathrm{Fe}_{0.02}\right)$ from $\sim 4$ to $20 \mathrm{~K}$. The corresponding volumetric heat capacities of the cryocooler prototype regenerator materials $\mathrm{Er}_{50} \mathrm{Pr}_{50}, \mathrm{HoCu}_{2}$ and $\mathrm{ErNi}$ are also shown.

$\mathrm{x}$ varies from 0 to 1.0 . In general, as $\mathrm{x}$ increases, the two ordering peaks shift slowly to higher temperatures.

\section{Transition Metal Additions}

The substitution of $\mathrm{Mn}, \mathrm{Fe}, \mathrm{Co}, \mathrm{Ni}$ and $\mathrm{Ru}$ for $\mathrm{Cu}$ in $\operatorname{Er}\left(\mathrm{Cu}_{1-\mathrm{x}} \mathrm{M}_{\mathrm{x}}\right)$ and $\operatorname{Tm}\left(\mathrm{Cu}_{1-\mathrm{x}} \mathrm{M}_{\mathrm{x}}\right)$ have been studied. Nominally $\mathrm{x}$ was 0.05 , but in some cases it was as large as 0.20 and as small as 0.02. In general, the two magnetic ordering peaks of the ErCu parent compound are shifted to lower temperatures, the upper one faster than the lower ordering peak, but only in the case of $\mathrm{Ru}$ additions did the two ordering temperatures merge. The volumetric heat capacities are significantly lowered, with $\mathrm{Co}$ additions having the largest effect followed by $\mathrm{Ni}, \mathrm{Fe}$ and $\mathrm{Mn}$ in that order.

For $\mathrm{TmCu}$, the transition metal substitutes caused the two magnetic ordering peaks to merge at $x \cong 0.05$. The heat capacity values at the ordering temperature are significantly reduced, again with $\mathrm{Co}$ having the greatest effect followed by $\mathrm{Ni}, \mathrm{Ru}$ and $\mathrm{Fe}$. The volumetric heat capacity of the $\mathrm{Tm}\left(\mathrm{Cu}_{0.98} \mathrm{Fe}_{0.02}\right)$ ductile intermetallic compound is shown in Fig. 4 along with the prototype regenerator materials $\mathrm{HoCu}_{2}, \mathrm{ErNi}$ and $\mathrm{Er}_{0.50} \mathrm{Pr}_{0.50}$. It is seen that the Fe doped alloy has a much better volumetric heat capacity between 5 to $8 \mathrm{~K}$ than $\mathrm{HoCu}_{2}$. But when compared to $\left(\mathrm{Tm}_{0.95} \mathrm{Y}_{0.05}\right) \mathrm{Cu}$ (Fig. 3 ) its heat capacity values are significantly smaller.

\section{Main Group Metal Additions}

The main group metals ( $\mathrm{M}=\mathrm{Al}, \mathrm{Zn}$ and $\mathrm{Ga}$ ), when substituted for $\mathrm{Cu}$ in the $\mathrm{ErCu}$, behave significantly different from the previous alloying agents. The lower ordering peak is shifted to higher temperatures and tends to merge with the upper magnetic ordering peak, and the heat capacity maximum is increased over the undoped $\mathrm{ErCu}$ material. For the $\mathrm{Al}$ and $\mathrm{Ga}$ additions at $\mathrm{x}=0.05$, these compounds have large heat capacities between 12 and $17 \mathrm{~K}$ (for $\mathrm{Al}$ ), and 12 and $18 \mathrm{~K}$ (for $\mathrm{Ga}$ ). The volumetric heat capacity for $\mathrm{Er}\left(\mathrm{Cu}_{0.95} \mathrm{Ga}_{0.05}\right)$ along with the prototype materials is shown in Fig. 5. As far as we are aware this alloy has the highest heat capacity in $15 \pm 3 \mathrm{~K}$ range of any know material.

The effect of $\mathrm{Al}$ and $\mathrm{Ga}$ substitutions for $\mathrm{Cu}$ in $\mathrm{TmCu}$ is different from that noted above for ErCu. In the Tm-based materials, the two ordering peaks merge between the two peaks of the $\mathrm{TmCu}$ compound, with a volumetric heat capacity value between those of the two peaks of 


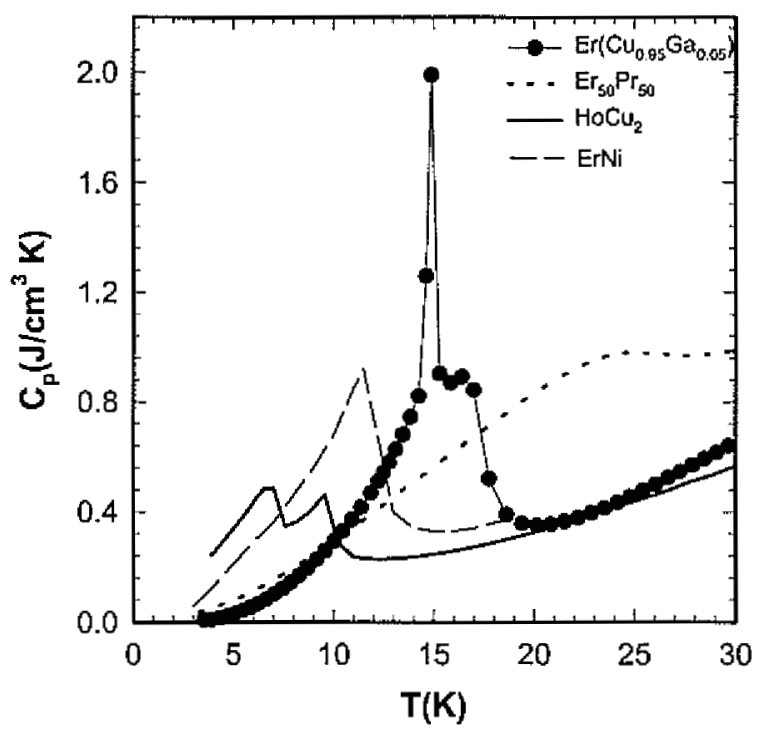

Figure 5. The volumetric heat capacity of $\operatorname{Er}\left(\mathrm{Cu}_{0.95} \mathrm{Ga}_{0.05}\right)$ from $\sim 3$ to $20 \mathrm{~K}$. The corresponding volumetric heat capacities of the cryocooler prototype regenerator materials $\mathrm{Er}_{50} \mathrm{Pr}_{50}, \mathrm{HoCu}_{2}$ and $\mathrm{ErNi}$ are also shown.

$\mathrm{TmCu}$. For the $\operatorname{Tm}\left(\mathrm{Cu}_{0.95} \mathrm{Al}_{0.05}\right)$ compound, the heat capacity is three times larger than that of $\mathrm{HoCu}_{2}$.

\section{Recommended Regenerator Materials}

Of the alloys studied, the best material for a regenerator which operates below $4 \mathrm{~K}$ is $\mathrm{ErRh}$, followed closely by ErIr, see Fig. 2. But because of the cost of Rh and $\mathrm{I} r$, these two intermetallic compounds would see limited use.

There are eleven $\mathrm{Er}$ - and Tm-based B2 CsCl-type intermetallic compounds that could be used as a replacement for $\mathrm{HoCu}_{2}$. The best is $\mathrm{TmCu}$, which has a maximum heat capacity value more than six times larger than that of $\mathrm{HoCu}_{2}$. However, when $5 \% \mathrm{Lu}$ is substituted for $\mathrm{Tm}$, i.e.

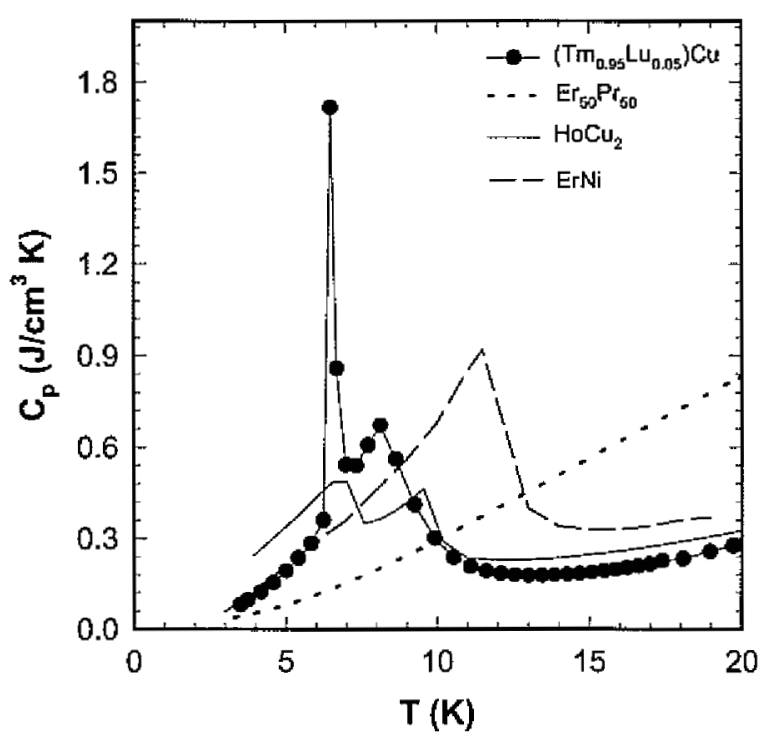

Figure 6. The volumetric heat capacity of $\left(\operatorname{Tm}_{0.95} \mathrm{Lu}_{0.05}\right) \mathrm{Cu}$ from $\sim 3$ to $20 \mathrm{~K}$. The corresponding volumetric heat capacities of the cryocooler prototype regenerator materials $\mathrm{Er}_{50} \mathrm{P}_{50}, \mathrm{HoCu}_{2}$ and $\mathrm{ErNi}$ are glen shnwm 


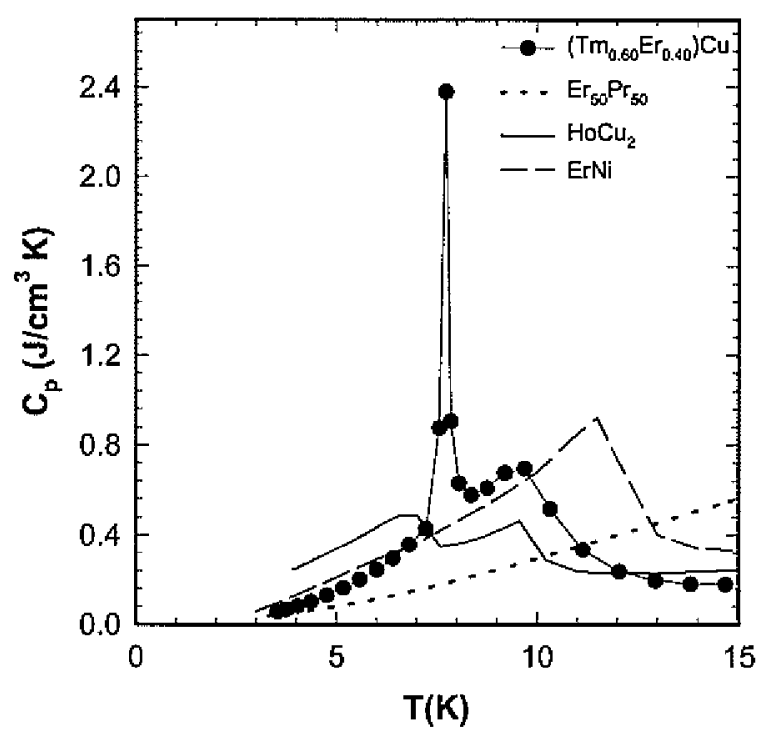

Figure 7. The volumetric heat capacity of $\left(\mathrm{Tm}_{0.60} \mathrm{Er}_{0.40}\right) \mathrm{Cu}$ from $\sim 3$ to $20 \mathrm{~K}$. The corresponding volumetric heat capacities of the cryocooler prototype regenerator materials $\mathrm{Er}_{50} \mathrm{Pr}_{50}, \mathrm{HoCu}_{2}$ and $\mathrm{ErNi}$ are also shown.

$\left(\mathrm{Tm}_{0.95} \mathrm{Lu}_{0.05}\right) \mathrm{Cu}$ the peak maximum is lowered by about half of that of $\mathrm{TmCu}$, but the breadth of the pair of peaks is wider and thus is more competitive with $\mathrm{HoCu}_{2}$, see Fig. 6 .

In the 6 to $9 \mathrm{~K}$ temperature range (i.e. between the $\mathrm{HoCu}_{2}$ peaks and the ErNi peak) there are four ErCu-based materials and three $\left(\mathrm{Tm}_{0.6} \mathrm{Er}_{0.4}\right) \mathrm{Cu}$ compounds which have significant heat capacities and could be used as regenerator materials covering this region. The best of these is $\left(\mathrm{Tm}_{0.6} \mathrm{Er}_{0.4}\right) \mathrm{Cu}$, see Fig. 7 .

There is one $\left(\mathrm{Tm}_{1-\mathrm{x}} \mathrm{Er}_{\mathrm{x}}\right) \mathrm{Cu}$ alloy which would be competitive with $\mathrm{ErNi}$ prototype regenerator material, namely $\left(\mathrm{Tm}_{0.2} \mathrm{Er}_{0.8}\right) \mathrm{Cu}$, see Fig. 8. As a matter of fact the performance of the two materials as regenerators would be expected to be nearly the same if the two compounds

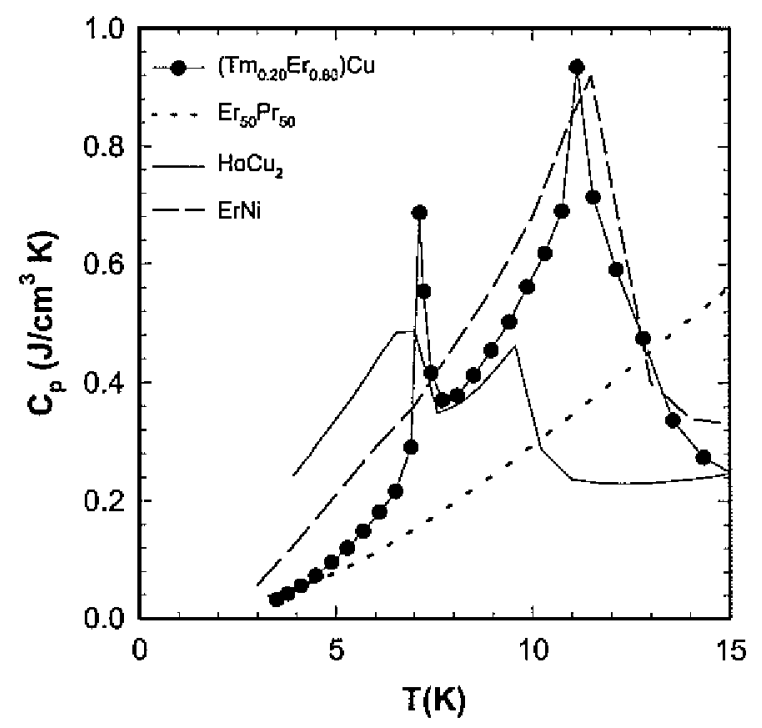

Figure 8. The volumetric heat capacity of $\left(\operatorname{Tm}_{0,20} \mathrm{Er}_{0,80}\right) \mathrm{Cu}$ from 3 to $20 \mathrm{~K}$. The corresponding volumetric heat capacities of the cryocooler prototype regenerator materials $\operatorname{Er}_{50} \mathrm{Pr}_{50}, \mathrm{HoCu}_{2}$ and $\mathrm{ErNi}$ are also shown. 


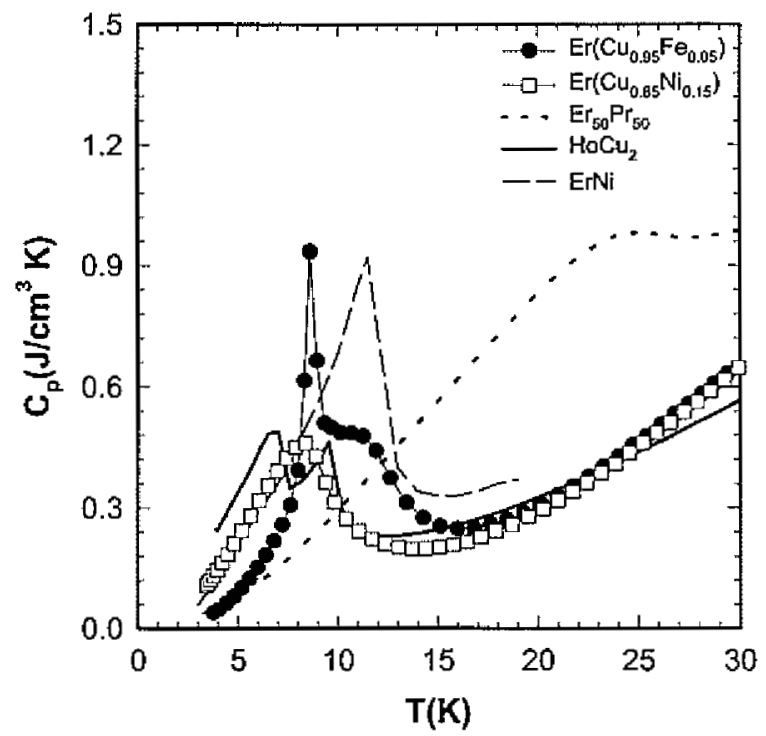

Figure 9. The volumetric heat capacities of $\operatorname{Er}\left(\mathrm{Cu}_{0.95} \mathrm{Fe}_{0.05}\right)$ and $\operatorname{Er}\left(\mathrm{Cu}_{0.85} \mathrm{Ni}_{0.15}\right)$ from $\sim 3$ to $30 \mathrm{~K}$. The corresponding volumetric heat capacities of the cryocooler prototype regenerator materials $\mathrm{Er}_{50} \mathrm{Pr}_{50}$, $\mathrm{HoCu}$, and ErNi are also shown.

were used as spheres. However, since $\left(\mathrm{Tm}_{0.2} \mathrm{Er}_{0.8}\right) \mathrm{Cu}$ is ductile, it can be fabricated into forms (parallel plates, monolithic perforated cylinders, etc.) which have much higher efficiencies than packed particle beds ${ }^{15}$. But since ErNi is a brittle intermetallic compound it is impossible, or nearly so, to fabricate into parallel plates, etc.

There is one major drawback to these Tm-based B2 intermetallic compounds, and that is the cost of Tm which can be 2 to 5 times more expensive than Er. There are, however, Er-based CsCl-type intermetallic compounds which are also better than the current prototypes, but they do not have nearly as large heat capacities as the Tm-based materials noted above. As a replacement for $\mathrm{HoCu}_{2}$, the $\mathrm{Er}\left(\mathrm{Cu}_{0.85} \mathrm{Ni}_{0.15}\right)$ alloy is the best Er-based material, while for the 6 to $9 \mathrm{~K}$ temperature range $\mathrm{Er}\left(\mathrm{Cu}_{0.95} \mathrm{Fe}_{0.05}\right)$ would be the choice material, see Fig. 9 .

For temperatures above $12 \mathrm{~K}$ there are three $\operatorname{Er}\left(\mathrm{Cu}_{0.95} \mathrm{M}_{0.05}\right)$ alloys, where $\mathrm{M}=\mathrm{Al}, \mathrm{Zn}$ and $\mathrm{Ga}$, which would make excellent regenerator materials. The best being $\mathrm{M}=\mathrm{Ga}$, see Fig. 5 .

\section{SUMMARY}

A large number of $\left(\mathrm{Er}_{1-\mathrm{x}} \mathrm{R}_{\mathrm{x}}\right) \mathrm{M}$ and $\left(\mathrm{Tm}_{\mathrm{I-x}} \mathrm{R}_{\mathrm{x}}\right) \mathrm{M}$ compounds have the $\mathrm{B} 2 \mathrm{CsCl}$-type crystal structure and are also ductile. Several of them have heat capacities below $15 \mathrm{~K}$, which are greater than those of the currently used prototype materials, such as $\mathrm{HoCu}_{2}, \mathrm{Er}_{3} \mathrm{Ni}$ and $\mathrm{ErNi}$. In addition because the Er- and Tm-based intermetallics with the B2 structure are ductile, they can be easily fabricated into more efficient regenerator forms, while this is nearly impossible to do for the prototype compounds because they are brittle intermetallics. Furthermore, it has been shown that in general the Tm-based compounds are far better materials than Er-based compounds as regenerator materials because of their much higher volumetric heat capacities. When the ductile Er- and Tm-based B2 intermetallic compounds are utilized as regenerator materials for cooling below $15 \mathrm{~K}$, the performances of cryocoolers will be improved, their efficiencies increased, and the no load temperatures will be lower as compared to the currently utilized regenerator materials $\left(\mathrm{HoCu}_{2}, \mathrm{Er}_{3} \mathrm{Ni}\right.$ and $\left.\mathrm{ErNi}\right)$.

\section{ACKNOWLEDGEMENTS}

Different aspects of this research were supported by Atlas Scientific, San Jose, California and by the Office of Basic Energy Sciences, Materials Sciences Division of the U.S. Department of Energy under Contract No. W-7405-ENG-82. 


\section{REFERENCES}

1. Buschow, K.H.J., Olijhoek, J.F. and Miedema, A.R., "Extremely Large Heat Capacities Between 4 and 10 K", Cryogenics, vol. 15 (1975), pp. 261-264.

2. Sahashi, M., Tokai, Y., Kuriyama, T., Nakagome, H., Li, R., Ogawa, M. and Hashimoto, T., "New Magnetic Material $\mathrm{R}_{3} \mathrm{~T}$ System with Extremely Large Heat Capacities Used as Heat Regenerators", Adv. Cryogen. Eng., vol. 35 (1990), pp. 1175-1182.

3. Kuryama, T., Hakamada, R., Nakagome, H., Tokai, Y., Sahashi, M., and Li, R., Yoshida, O., Matsumoto, K. and Hashimoto, T., "High Efficient Two-State GM Refrigerator with Magnetic Materials in Liquid Helium Temperature Region", Adv. Cryogen. Eng., vol. 35, (1990), pp. 12611269.

4. Ackerman, R.A., Cryogenic Regenerative Heat Exchangers, Plenum Press, New York, 1997, p. 98.

5. Satoh, T., Onishi, A., Umehara, I., Adachi, Y., Sato, K, and Minehara, E.J., "A Gifford-McMahon Cycle Cryocooler Below 2 K", Cryocoolers 11, edited by R.G. Ross, Jr., Kluwer Academic/Plenum Publishers, New York, (2001) pp. 381-386.

6. Gschneidner, K.A., Jr., Pecharsky, A.O. and Pecharsky, V.K., "Ductile, High Heat Capacity, Magnetic Regenerator Alloys for the 10 to $80 \mathrm{~K}$ Temperature Range", Cryocoolers 11, edited by R.G. Ross, Jr., Kluwer Academic/Plenum Publishers, New York, 2001, pp. 433-441.

7. Kashani, A., Helvensteijn, B.P.M., Maddocks, J.R., Kittel, P., Feller, J.R., Gschneidner, K.A., Jr., Pecharsky, V.K. and Pecharsky, A.O., "Performance of a New Regenerator Material in a Pulse Tube Cooler", Adv. Cryogenic Eng., vol. 47, pp. 985-991 (2002).

8. Tanaeva, I.A., Ikeda, H., van Bokhoven, L.J.A., Matsubara, Y., and de Waele, A.T.A., "Heat Capacities and Magnetic Moments of Potential Regenerator Materials at Low Temperatures", Cryogenics vol. 43, pp. 441-448 (2003).

9. Pecharsky, V.K., Moorman, J.O., and Gschneidner, K.A., Jr., "A 3-350 K Fast Automatic Small Sample Calorimeter", Rev. Sci. Instrum. vol. 68, pp. 4196-4207 (1997).

10. Gschneidner, K. Jr., Russell, A., Pecharsky, A., Morris, J., Zhang, Z., Lograsso, T., Hsu, D., Lo, C.H.C., Ye, Y., Slager, A. and Kesse, D., "A Family of Ductile Intermetallic Compounds", Nature Materials vol. 2, pp. 587-590 (2003).

11. Morin, P., and Schmidt, D., "Competition Between Multi-q Antiferromagnetic Structures in Cubic Rare Earth-Copper Compounds", J. Magn. Magn. Mater. vol. 21, 243-256 (1980).

12. Hill, R.W., "The Specific Heats of ErAg and TbAg Between 0.5 and $21 \mathrm{~K}$ ", J. Phys. F: Met. Phys. vol. 17, pp. 243-255 (1987).

13. Rawat, R. and Das, I, "The Similar Dependence of the Magnetocaloric Effect and Magneto-resistance in TmCu and TmAg Compounds and Its Implications", J. Phys. Condens. Matter vol. 13, L379-L387 (2001).

14. Biwa, T., Yagi, W. and Mizutani, U., "Evaluation of Low-temperature Specific Heats and Thermal Conductivities of Er-Ag Alloys as Regenerator Materials", Jpn. J. Appl. Phys. vol. 35, 2244-2248 (1996).

15. Barclay, J.A. and Sarangi, S., "Selection of Regenerator Geometry for Magnetic Refrigeration Applications", A.S.M.E. Annual Winter meeting, New Orleans, (December 1984). 